Old Dominion University

ODU Digital Commons

Human Movement Sciences Faculty

Publications

Human Movement Sciences

$11-2021$

\title{
Risk Communication in the Tourism Industry
}

Lindsay E. Usher

Old Dominion University, lusher@odu.edu

Ashley Schroeder

The Pennsylvania State University

Follow this and additional works at: https://digitalcommons.odu.edu/hms_fac_pubs

Part of the Climate Commons, Communication Commons, Emergency and Disaster Management

Commons, Environmental Policy Commons, and the Tourism and Travel Commons

\section{Original Publication Citation}

Usher, L. E., \& Schroeder, A. (2021). Risk communication in the tourism industry. In J.E.W. Yusuf \& B. St. John III (Eds.), Communicating Climate Change: Making Environmental Messaging Accessible (pp.151-168). Routledge.

This Book Chapter is brought to you for free and open access by the Human Movement Sciences at ODU Digital Commons. It has been accepted for inclusion in Human Movement Sciences Faculty Publications by an authorized administrator of ODU Digital Commons. For more information, please contact digitalcommons@odu.edu. 


\title{
Risk Communication in the Tourism Industry
}

Lindsay E. Usher

Old Dominion University

USA

Ashley Schroeder

The Pennsylvania State University

USA

(Authors' submitted version for inclusion in the book Communicating Climate Change: Making Environmental Messaging Accessible, edited by Juita-Elena (Wie) Yusuf and Burton St. John III)

\begin{abstract}
This chapter focuses on risk communication in the tourism sector. Tourism organizations must communicate with a variety of stakeholders when conveying messages about impending severe weather or disasters, which are increasing due climate change and sea level rise. There is also an increased need to distribute information to tourism stakeholders about preparing for, continuing service during, and recovering from, disasters. Stakeholders involved with the tourism industry include business owners, government officials and tourists, all of whom have differing degrees of vulnerability in a destination when a threat occurs. Different messages regarding disaster preparation and recovery must be communicated to the different stakeholders, and often industry associations or convention and visitors' bureaus are responsible for relaying these messages. The chapter provides an overview of previous research on risk communication. The authors then detail a case study about improving risk communication and information among tourism stakeholders in coastal Virginia. The chapter concludes with lessons for public officials, destination management organizations, and tourism business owners to improve their risk communication.
\end{abstract}




\section{Introduction}

Amid the worldwide coronavirus pandemic, which began in late 2019, there have been calls for more socially, economically, and environmentally just forms of tourism (Benjamin, Dillette, \& Alderman, 2020). In a time of lower numbers of tourists moving around the globe, scholars argue that now is the time to "upgrade" tourism to a better version that is less harmful to local people and environments. If we are going to revise the tourism industry to be more sustainable and responsible, we should also make it more resilient in the process. Resilience is not the same as sustainability (Espiner, Orchiston, \& Higham, 2017). In the context of climate change, resilience is the adaptive capacity of a tourism business or destination to overcome disruptions due to, for example, severe weather events and disasters (Usher, Yusuf, \& Covi, 2019). The world will continue to face global crises due to climate change and sea level rise, and the tourism industry must be better prepared to face that reality. The current pandemic provides a stark reminder of ways in which multiple crises can intersect and exacerbate already severe problems. With a record-setting 2020 hurricane season in the Atlantic, emergency managers had to contemplate ways that social distancing measures could be implemented in hurricane shelters (Centers for Disease Control and Prevention, 2020; NOAA, 2020). Tourism practitioners were forced to deal with this new multiple-disaster-ridden reality as well, as hotels were sought out as places to safely house (and space out) hurricane evacuees, as well as quarantine people with COVID-19 exposure (McCullough \& Garnham, 2020; Palus, 2020).

Coastal communities, many of which are economically dependent upon tourism, are on the front lines of sea level rise and climate change: they are witnessing more regular flooding events and increasingly severe storms (Leatherman, 2017; Atzori \& Fyall, 2018). Tourism businesses and 
destinations must be resilient to withstand the current constantly changing environment. However, previous research found that the tourism industry tends to have a reactive, rather than proactive, approach to disasters, leading to lower levels of resilience because business owners and tourism organizations have not done adequate planning (Ritchie, 2004; Brown, Rovins, Feldmann-Jensen, Orchiston, \& Johnston, 2017). Many smaller businesses do not have the time and resources to dedicate to comprehensive business resilience planning until there is an impending severe weather event (Hall, 2006; Calgaro, Dominey-Howes, \& Lloyd, 2014; Brown et al., 2017; Usher et al., 2019).

Research has shown that collaboration and communication among local tourism organizations, business owners, and local government officials is a key aspect of tourism business and destination resilience to disasters (Pennington-Gray, Schroeder, \& Gale, 2014; Jiang \& Ritchie, 2017). However, tourism organizations and businesses must not only communicate among themselves, but with the public, guests, and staff as well, and the messaging is not the same for everyone. Therefore, the need to communicate accurate information regarding climate change in appropriate ways is crucial within tourism destinations. This chapter explores this communication need further. The first section provides an overview of pertinent previous research that has been done on risk communication. We then detail a case study from the coastal region of Virginia associated with communicating severe weather risk and resilience to tourism stakeholders through workshops and an online tool developed in 2018. We conclude this chapter with lessons for tourism stakeholders to improve their communication to various groups within the tourism destination. 


\section{Risk communication}

Due to climate change and the global rise in frequency and intensity of disasters, it is important for all members of the tourism system to have a way to communicate about existing and emerging risks. These risks need to be communicated not only among managers in the tourism industry, but also with the general public, the traveling public, employees working in the tourism industry, and those in related sectors (e.g., transportation, food service, retail). Risk communication messages should be tailored to each audience. To do so, we must first understand the central tenets of risk communication.

While there are many definitions of risk communication, comparing and contrasting them can help to provide foundational knowledge for effective risk communication. The World Health Organization (WHO, n.d.) defines risk communication as "the exchange of real-time information, advice and opinions between experts and people facing threats to their health, economic or social well-being." Morgan, Fischoff, Bostrom and Atman (2002) defined risk communication as the process by which people become informed about safety, health and environmental risks or hazards, and are influenced to make informed judgments, decisions, and behaviors. Covello (1992) described risk communication as the "process of exchanging information among interested parties about the nature, magnitude, significance, or control of a risk" (p. 359). Combined, these definitions reveal a consensus that risk communication is a process for information exchange between multiple stakeholders who are facing risk. They also reveal an emphasis on acquiring knowledge that should result in informed decision-making and prompt action. 
People must be aware of the types of risks that they face, as well as what they can do to protect themselves and others (WHO, 2018). The objectives of risk communication are to increase knowledge and comprehension, build and maintain trust and credibility, and support people in taking recommended behaviors (United States Nuclear Regulatory Commission/U.S. NRC, 'Risk Communication - Principles, Tools, \& Techniques'). Engaging in effective risk communication requires a foundational understanding of the knowledge, abilities, attitudes, behaviors, beliefs, perceptions, and worries of people (WHO, n.d.). It also requires an understanding and knowledge of cultures, as well as the resultant building of social trust (WHO, 2018). According to Dr. Gaya Gamhewage (Manager of Support for Response in the Infectious Hazard Management Department of the WHO Health Emergencies Programme), risk communication needs to "be linked to accessible services, provision of timely, easy to understand information through the use of multiple platforms, methods and channels," and must practice "transparency by acknowledging uncertainty and directly addressing the affected populations" in order to be effective (WHO, 2018).

Traditionally, the focus of risk communication has been on messaging. However, while the message is important, more recent disasters have highlighted the fact that trust is needed for affected people to listen to risk communication messages (WHO, 2018). Dirks and Ferrin (2001) consider trust to be "an expectation or belief that one can rely upon another person's actions and words, and/or that the person has good intentions" (as cited in Li, 2005, p. 85). If trust has not been built, people have a higher likelihood of ignoring these messages (WHO, 2018). Given that research supports the notion that trust and credibility are part of the foundation of effective risk 
communication (Covello, 1993), it is important to recognize that building and maintaining trust is a time-intensive endeavor that requires great effort. This is not a quick process. Rather, trust and credibility are built over time (Covello, 1993). It also plays a foundational role in the risk management process and needs to be continually nurtured. In other words, building and maintaining trust should be an objective in the reduction, readiness, response, and recovery phases of a crisis, emergency, or disaster.

Dr. Vinya Ariyaratne (General Secretary of the Sarvodaya Shramadana Movement in Sri Lanka), building on his experience, said that two requisites of trust are that community members are aware of the facts and are confident in the source, whether that be a person, institution, or organization (WHO, 2018). He also stressed the importance of community empowerment in building trust. As part of this process, community members should be included in the decisionmaking process related to risk management and in the development of strategies to manage risks (WHO, 2018). Covello $(1992,1993)$ identified four variables that influence people's perceptions of trust and credibility in risk communication: (1) caring and empathy, (2) dedication and commitment, (3) competence and expertise, and (4) honesty and openness. These determinants are evident in Renn and Levine's (1991) definition of trust in the context of risk communication "the generalized expectancy that a message received is true and reliable and that the communicator demonstrates competence and honesty by conveying accurate, objective, and complete information" (p. 179). The four variables also happen to be fundamental components of persuasive communication (Brehm, Kassin, \& Fein, 2005). The effectiveness of risk communication is determined, in part, by "the degree to which all actions and communications by the [source] - verbal and nonverbal - convey" each of these variables (Covello, 1993, p. 18). 
According to Covello (1993), caring and empathy are the most important determinants of trust and credibility, as they typically account for up to half of the variance in perceptions of trust and credibility. The other three sets of determinants each typically account for $15 \%$ to $20 \%$ of the variance in perceptions of trust and credibility (Covello, 1993).

Perceptions of caring and empathy are based mostly on cues that the source is making "a sincere effort to understand how it would feel to be in the stakeholder's position" (U.S. NRC, 'Effective Risk Communication - The Nuclear Regulatory Commission's Guidelines for External Risk Communication,' p. 13). These perceptions are typically formed quickly - in as little as 30 seconds - and are difficult to change once formed. Perceptions of competence and expertise are based mostly on "the degree of technical expertise assigned to a message or a source" (Renn \& Levine, 1991, p. 179). On the other hand, perceptions of honesty and openness are based mostly on "verbal, nonverbal, and performance cues that the [source] is truthful, candid, just, fair, objective, and accessible" (Covello, 1993, p. 19). With this determinant, nonverbal cues (e.g., eye contact, physical barriers between the source and the receiver, etc.) are extremely important. Perceptions of dedication and commitment are based mostly on cues that the source is dedicated "to ensuring public safety and to openly communicating with stakeholders to understand their perspectives and to help them understand yours" (U.S. NRC, Effective Risk Communication The Nuclear Regulatory Commission's Guidelines for External Risk Communication,' p. 13). If a source does not communicate about their dedication and commitment, it can have a significant negative effect on trust and credibility (Covello, 1993). An example could be a tourism destination not having a banner on their website to notify people of a risk and not using their 
social media channels to provide up-to-date information about the situation and what they are doing to ensure visitor safety.

Other factors have also been found to influence perceptions of trust and credibility. For example, a study conducted by Peters, Covello, and McCallum (1996) provided empirical support for the hypothesis that higher amounts of risk-related information received from a source were related to higher levels of trust in that source. Risk-related information may include, but is not limited to, public notification of a potential risk and plans developed to manage a risk. For example, tourism businesses may notify tourists who are onsite about an approaching hurricane and what is being done to keep them safe, as well as what the tourists should do to keep themselves safe. In addition, it was suggested that the quality of such information also likely affects perceptions of trust and credibility (Peters, Covello, \& McCallum, 1996).

\section{Case study: Tourism business resilience workshops and online assessment}

Building trust involves community empowerment (WHO, 2018). In the context of risk communication in tourism, it is important to include tourism industry stakeholders in the decision-making process and the development of strategies to manage risks (WHO, 2018). Furthermore, collaboration and communication among tourism industry stakeholders is an important part of ensuring that tourism businesses and destinations will bounce back from disasters (Pennington-Gray et al., 2014; Jiang \& Ritchie, 2017). This chapter describes the Coastal Virginia Tourism Business Resilience Workshops and Online Self-Assessment Project, which was an extension of the Tourism Business Resilience for Coastal Virginia Assessment Project conducted in 2016-17 for the Commonwealth Center for Recurrent Flooding Resiliency. ${ }^{1}$ 
This 2016-17 assessment centered on the tourism industry of the City of Virginia Beach, located in the coastal area of Virginia known as Hampton Roads, and found that many franchisees and independent small businesses in the Virginia Beach Oceanfront area were not as prepared for, or resilient to, coastal hazards and flooding as some of the large brand-name hotels (Usher, et al., 2019). As a result, the CCRFR identified the need to make resilience resources more broadly available to all tourism and service industry businesses in the Hampton Roads region. The project was intended to meet this need by conducting Tourism Business Resilience workshops and developing an online resource to support self-assessment of business resilience by owners and managers of tourism-related businesses. Three workshops were planned for Norfolk, Virginia Beach, and Williamsburg, the three communities in the region with large tourism sectors. To provide business owners and managers with broader access to a wider range of resilience-related resources, this project developed the online Coastal Virginia Tourism Business Resilience Self-Assessment tool so that business owners and managers could conduct a selfassessment of their organization's resilience and find resources for building resilience.

\section{Tourism business resilience workshops}

The workshops were scheduled for the off-season (February) to provide tourism business owners and managers the best opportunity to attend. Workshop announcements and invitations were disseminated to a variety of community tourism organizations and business associations with a request to share this information with their members. A press release about the workshops was sent to local media outlets. In-person announcements were made and flyers distributed at local business association meetings. Due to a low number of advance registrations for the Norfolk location, the workshop was canceled and interested parties were redirected to the other two 
workshops. Twenty-nine people registered for the Virginia Beach workshop and approximately 17 people attended. Most participants were from Destination Management Organizations (DMOs), accommodations, attractions, and restaurant sectors. DMOs are agencies, such as convention and visitors' bureaus, that market the destination to travelers, often represent and facilitate cooperation among local tourism businesses, and are responsible for coordinating the development of the destination. Nineteen individuals registered for the Williamsburg workshop and 17 people attended. Most participants were from local government organizations and businesses in sectors other than those originally targeted (hotels, restaurants, retail, attractions, or tours), including a restoration company and a Pilates studio owner.

Both the Virginia Beach and Williamsburg workshops lasted approximately four hours (see Figure 9.1 for an example of the workshop agenda). Breakfast and lunch were provided and allowed for additional networking and discussion opportunities. The workshop began with a presentation explaining flood risk and sea level rise, the implications for tourism businesses specifically, and the meaning of resilience. This presentation was followed by an audience response system (or "clickers") activity to assess workshop participants' risk perceptions and preparedness regarding sea level rise. During this activity, one researcher asked participants to select responses regarding their business' vulnerability to flooding, preparedness for severe weather events, ability to maintain business operations during a severe weather event, and communication channels with staff and guests; the results were immediately shared with participants so they could compare their responses to other workshop participants. The results were also discussed in the context of key findings of the Tourism Business Resilience for Coastal 
Virginia Assessment (focused on the Virginia Beach Oceanfront) previously conducted in 2016-

17. 
Figure 9.1: Example of agenda for the Coastal Virginia Tourism Business Resilience Workshops.

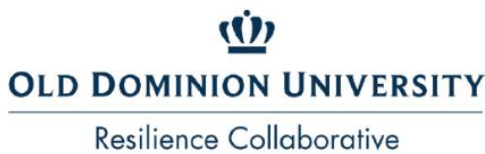

Resilience Collaborative

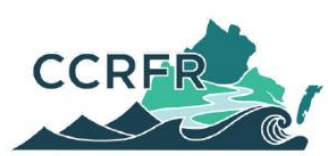

WILLIAM ङ゚ MARY

LAW SCHOOL

VIRGINIA COASTAL

POLICY CENTER

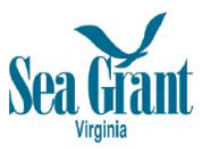

\section{Tourism Business Resilience Workshop \\ February 28, 2018}

\begin{tabular}{|l|l|}
\hline 8:30 AM - 9:00 AM & Check in and coffee \\
\hline 9:00 AM - 9:15 AM & $\begin{array}{l}\text { Opening Remarks and Introductions } \\
\text { Karen Riordian, Greater Williamsburg Chamber and Tourism Alliance }\end{array}$ \\
\hline 9:15 AM - 10:15 AM & $\begin{array}{l}\text { Keynote } \\
\text { Jim and Annemarie Dickerson, owners of Francis Scott Key Resort }\end{array}$ \\
\hline 10:15 AM - 10:30 AM & Break/Continental Breakfast \\
\hline 10:30 AM - 11:15 AM & $\begin{array}{l}\text { Severe Weather Risk and Resilience in Coastal Virginia } \\
\text { Dr. Michelle Covi, Old Dominion University and Virginia Sea Grant } \\
\text { Dr. Lindsay Usher, Old Dominion University }\end{array}$ \\
\hline 11:15 AM- 11:45 AM & Interactive Self-Assessment \\
\hline 11:45 AM - 12:15 PM & Lunch \\
\hline 12:15 PM- 1:00 PM & Resilience Planning Activity \\
\hline 1:00 PM & Wrap Up \\
\hline
\end{tabular}

Thank you to our sponsors
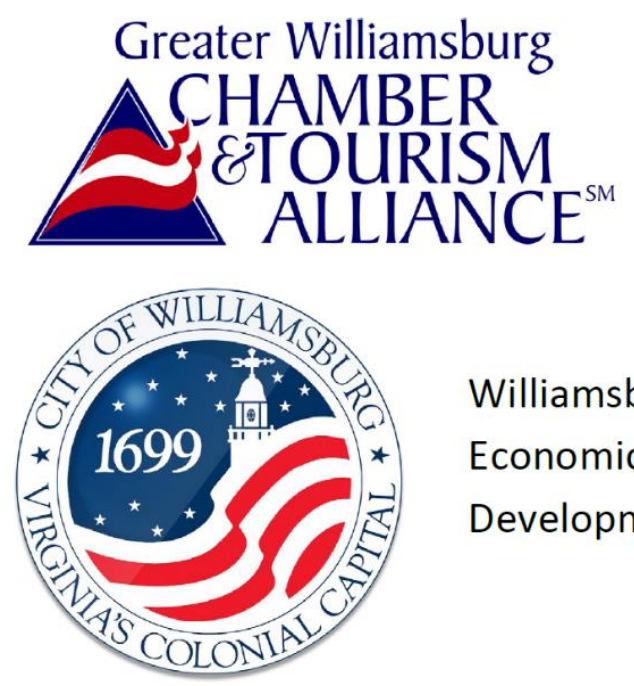

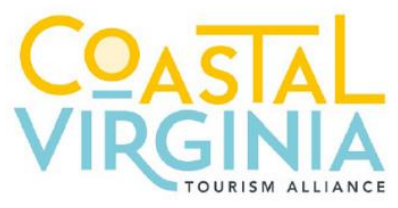

Williamsburg

Economic

Development

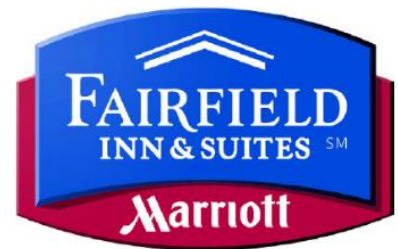


After a short break, participants were given printed copies of the Coastal Virginia Tourism Business Resilience Self-Assessment (this was a paper version of the online tool researchers created that will be described in detail in a later section of this chapter). Participants were asked to work through the self-assessment for their business or organization. Participants discussed the self-assessment with one another as they filled it out. Once participants had completed the selfassessment, they were prompted to consider areas where the self-assessment identified their business or organization to be lacking in resilience. Once participants determined the areas they needed to address, they were asked to pick and choose from selected worksheets and additional resources that were made available for participants to consult and take with them. During the workshop, facilitators also showed participants the self-assessment online tool (Figure 9.1), provided the web address for the online tool, and encouraged participants to visit the online tool to access many of the worksheets and resources (details about this self-assessment online tool will be provided in a later section of this chapter).

In the workshop held in Williamsburg, the flood risk and tourism resilience presentation was tailored for that city by using local flood maps and highlighting the tourism implications of power outages from hurricanes and road closures due to snowstorms: impacts from natural hazards that participants could relate to. Selected worksheets and resources were organized into stations according to the different topics of the online self-assessment tool (preparedness, continuity, communications, etc.) and participants were directed to go to the topic station for which they thought their business needed the most help. Case studies from the Virginia Beach Oceanfront tourism resilience assessment, and from Hurricane Katrina and Superstorm Sandy were provided at each of the stations to give participants examples and reference materials. 
During a hands-on activity, workshop facilitators asked participants at each station to come up with some specific actions a business owner could take to improve their preparedness, continuity, or other resilience dimensions at that station.

Both workshops included a keynote presentation by owners of a hotel in Maryland who also had a tourism business on St. Maarten island in the Caribbean. In their presentation, they described the ways in which their business in St. Maarten had been affected by Hurricane Irma in September 2017 and their process of recovery. They discussed lessons they had learned throughout the event, as well as changes they had made to their business plan for their property in Maryland in case a major storm ever hit the resort.

\section{Workshop evaluations}

At the conclusion of each workshop, participants were asked to complete an evaluation survey. Twenty-three workshop participants filled out these surveys. In terms of the types of businesses that participants owned or managed, six participants managed accommodations, one managed an attraction, one was a tour operator or provider, and the rest were "other." Some examples of “other" included a restoration company, a local government, DMOs, and an environmental organization.

When asked about their planning before the workshop, 13 participants had a preparedness plan for large and small disasters for their business, six had a plan for small-scale disasters, and four had no preparedness plan. Four participants said they had a written continuity plan prepared with a professional such as an insurance agent. Nine had "some kind of" continuity plan, three had an 
unwritten continuity plan, and six did not have a plan. When asked what they planned to do after the workshop, 16 participants said they were "likely" or "very likely" to create a preparedness plan and a business continuity plan. Seven participants who stated they already had preparedness plans and six who stated they already had business continuity plans.

When asked how they would rate their knowledge of the vulnerability of tourism businesses to coastal hazards after the workshop, one participant said their knowledge was "less than before," two said "same as before," 13 said "more than before," and seven said "much more than before." As far as their knowledge of the characteristics of a resilient tourism business, one person said their knowledge was "same as before," 12 said it was "more than before," and 10 said it was "much more than before."

All participants said that the material presented in the workshop was easy to understand. When asked how likely they were to use the materials provided to plan for their business, one participant answered, "somewhat likely," eight answered "likely" and 13 answered "very likely." Twenty-two participants answered they were "likely" or "very likely" to reference the online self-assessment to plan for their business' resilience.

Participants also answered a series of questions related to the usefulness of the workshop activities (Table 9.1). Based on the high means of most of the items, participants seemed to find many aspects of the workshop useful. Participants rated the guest speakers' presentation the highest $(M=4.70)$. Participants also appeared to appreciate the presentation about vulnerability and resilience. While "identifying relevant resilience activities" was rated the lowest, it was still 
above 4 on the 5-point scale, indicating high utility for participants. Table 2 presents

participants' impressions of the workshop overall. They again rated the guest speakers highly

and indicated they found it "educational and informative." Participants also seemed to find the workshop engaging and the materials useful for their business, based on the high average rates of agreement for those items.

Table 9.1: Participants' responses to questions about the usefulness of workshop activities (1=Not at all useful and 5=Very Useful).

\begin{tabular}{|l|c|c|c|}
\hline Item & $\boldsymbol{N}$ & Mean & SD \\
\hline Presentation about vulnerability and resilience & 22 & 4.55 & .51 \\
\hline Filling out the self-assessment & 22 & 4.27 & .98 \\
\hline Discussing self-assessment with peers & 22 & 4.27 & .70 \\
\hline $\begin{array}{l}\text { Identifying relevant resilience activities after } \\
\text { completing the self-assessment }\end{array}$ & 22 & 4.18 & .85 \\
\hline $\begin{array}{l}\text { Working with peers on resilience activities based } \\
\text { on results of the self-assessment }\end{array}$ & 20 & 4.25 & .79 \\
\hline Lunch guest speaker(s) & 20 & 4.70 & .47 \\
\hline
\end{tabular}

Table 9.2: Participants' responses to questions about the overall workshop ( $1=$ Strongly Disagree, 5=Strongly Agree).

\begin{tabular}{|l|c|c|c|}
\hline Item & $\boldsymbol{N}$ & Mean & $\boldsymbol{S D}$ \\
\hline Educational and informative & 23 & 4.74 & .45 \\
\hline Highly interactive and engaging & 23 & 4.57 & .51 \\
\hline Appropriate length of time & 23 & 4.39 & .78 \\
\hline Interesting guest speaker(s) & 23 & 4.74 & .45 \\
\hline $\begin{array}{l}\text { Provided opportunities for networking with my } \\
\text { peers }\end{array}$ & 23 & 4.48 & .51 \\
\hline $\begin{array}{l}\text { Provided useful materials for improving the } \\
\text { resilience of my business }\end{array}$ & 22 & 4.55 & .60 \\
\hline
\end{tabular}

When asked what they liked most about the workshop, participants said they liked the keynote presentation, the handouts, discussion and networking with other participants, and the useful 
information. One participant stated they were excited to share the information with business owners. Several participants suggested making the workshop shorter, and several participants wanted to see specific examples of the different types of plans. Another participant suggested bringing the workshop to the local chambers of commerce in Hampton Roads.

\section{Online self-assessment tool}

The Coastal Virginia Tourism Business Resilience Self-Assessment online tool was officially launched during the Tourism Business Resilience Workshop in Virginia Beach. ${ }^{2}$ Figure 9.2 provides a screenshot of the main page of the tool. The online tool provides a simple and inexpensive way for tourism businesses to determine if they are prepared for, and able to maintain operations during and after coastal hazards, disasters, and extreme events. Completing the self-assessment and reviewing the linked supplemental materials can assist tourism and service industry business owners and managers in building resilience. Users start on the first page, which includes an introduction and instructions. The next page asks users a series of questions about the vulnerability of their business. This online assessment does not provide the business with a resilience score; instead, each question encourages the user to consider whether their business has the necessary factors to be resilient. After a quiz, a link is provided that directs the user to websites or worksheets that have more information to assist users in planning and learning more about ways to become resilient. Figure 9.3 shows the order of the different dimensions of resilience the user would navigate through if they worked through the assessment from start to finish. The site does not link response data to the individual users, which hopefully encourages businesses to use it and be honest about their own resilience. 
Figure 9.2: Main page of the Coastal Virginia Tourism Business Resilience Self-Assessment online tool.

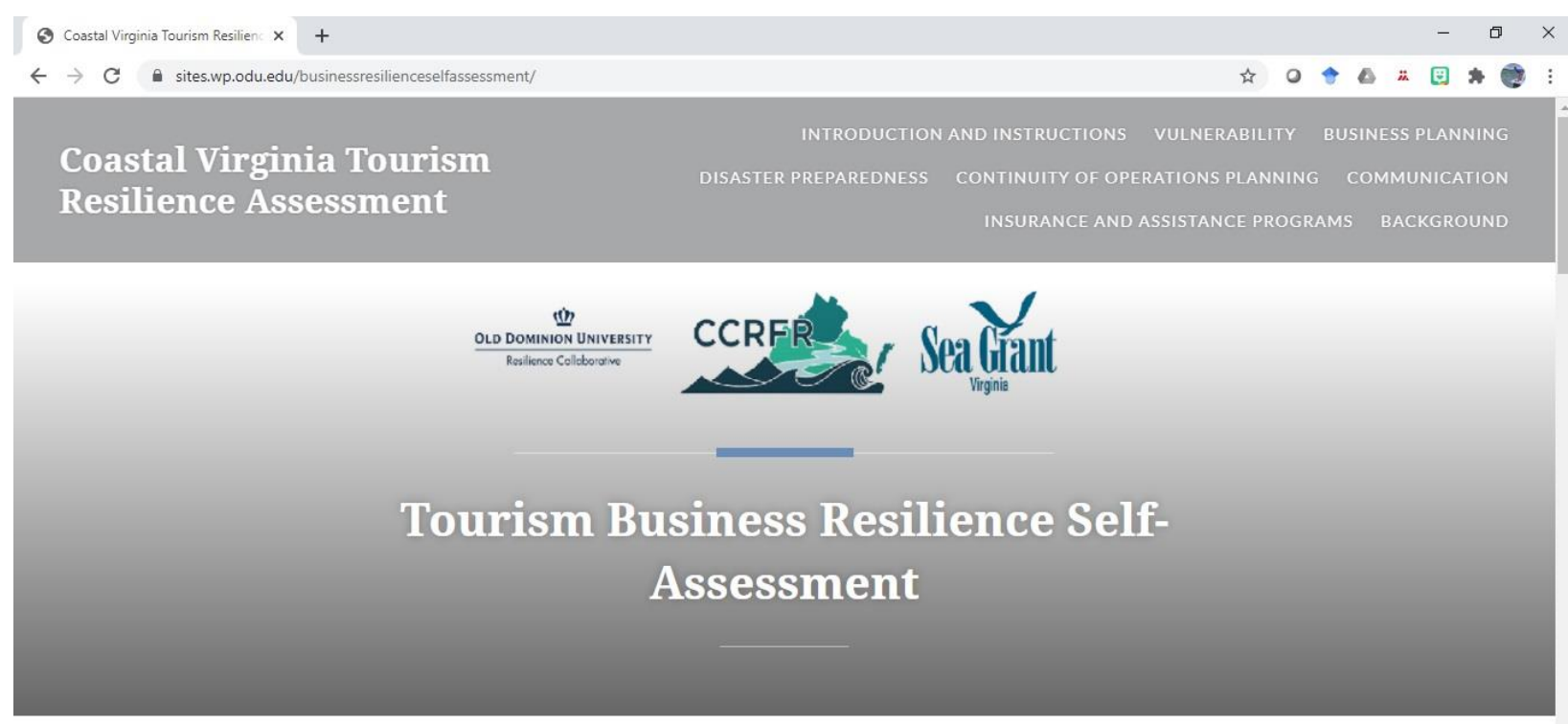

Figure 9.3: Dimensions of resilience included in the Coastal Virginia Tourism Business

Resilience Self-Assessment online tool.

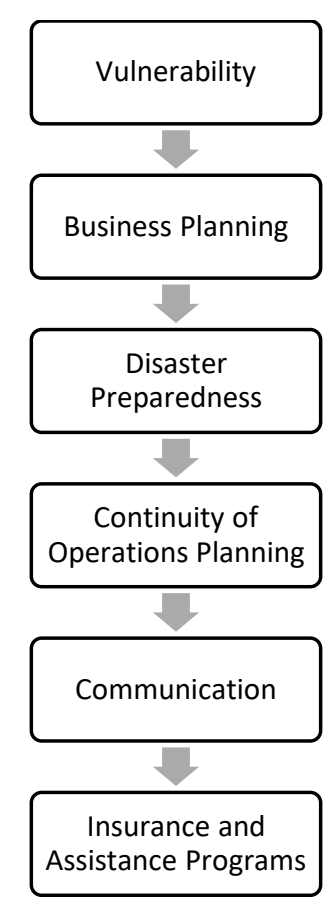




\section{Workshop and online self-assessment tool conclusions}

In terms of communicating to the tourism industry aspects of flood risk, sea level rise, and resilience, these workshops were moderately successful. There was substantial local support for the workshops; in-kind and monetary donations from local organizations made it possible to offer two workshops. Workshop participants seemed to benefit from the information provided and the workshop activities. Most participants indicated that the workshops had increased their knowledge about vulnerability and resilience. They also planned to use the materials for future planning. However, attendance was lower than initially anticipated, and many participants represented local tourism organizations, instead of business owners and managers who could directly benefit from the workshops.

Accordingly, the biggest challenges faced by the project team was creating awareness about the workshops and encouraging participation. While many local organizations helped disseminate information about the workshops, there were others that did not respond or were never reached. The duration of the workshop (half a workday or approximately four hours) appeared to be a substantial constraint for many business owners and managers, and a likely reason for low attendance. Lack of participation also may suggest that business owners have more immediate priorities than attending a workshop to learn about improving preparedness and business continuity for a severe weather event that may or may not occur. While parts of the workshop could be shortened into a one-hour format, having guest speakers who shared their own experiences added more time to the workshop but was, according to attendees, one of the most informative aspects of the workshop. Other challenges were that some of the workshop activities 
were not relevant to participants, such as those from DMOs, who did not own or manage a business. While the handouts and case studies were provided to assist participants in completing the activities, other participants seemed overwhelmed by the number of materials and resources available. While some of the handouts were meant to be filled out during the workshop, others were meant as takeaways and the facilitators could have provided those materials at the end. Participants also expressed a desire to have an example of preparedness and continuity plans. While the worksheets supplied were plan templates, the project team could have shown a plan from an actual business to provide an example of a final planning product.

After the workshops, members of the project team attended tourism and business association meetings locally to share the online self-assessment tool. They passed out cards with information about the online self-assessment tool and asked the associations to share the information with their members. Project team members also attended several conferences (e.g., the Virginia Green Travel Alliance Annual Conference, the Social Coast Forum) where they shared information about the online tool. The online tool provides a way for busy owners, who do not have time to attend a long workshop, to assess the resilience of their business at a time that is convenient for them. The COVID-19 crisis has led many people to realize how unprepared all industries have been in keeping their business resilient in the face of a major disruptive event such as a pandemic. In fact, community health is an essential dimension of resilience that needs to be added to the online business resilience self-assessment tool in the future.

This case study provides important insights on aspects of risk communication to tourism industry stakeholders. Public and private tourism stakeholders, such as those who attended the 
workshops, are receptive to information about vulnerability and resilience when given the opportunity to learn about it. Recognizing the scarcity of tourism business owners' time for additional training and professional development is another aspect that this study highlights. Existing professional associations and networks within the tourism industry are key in promoting and marketing educational and training opportunities about risk and resilience planning. These networks are also crucial in distributing planning resources, such as the online self-assessment tool. These insights can assist educational institutions and other agencies that wish to support the tourism industry in building resilience as severe weather events increase in the coming decades. Additional lessons for tourism industry stakeholders are outlined in the next section.

\section{Lessons for tourism industry stakeholders}

The research on risk communication and the case study presented in this chapter provide some important lessons for stakeholders about communicating risk to, and within, the tourism industry especially as it relates to the potential impacts of climate change. The following section details these lessons for different groups connected to the industry.

\section{Lessons for public officials}

For destinations where tourism is a major economic generator, partnerships between local government and tourism business associations and industry are key. Given the vital importance of tourism to coastal communities, a representative of the tourism industry should have a seat at the table in the emergency operations center (EOC). This is the case in Florida and Hawaii, where a representative of the State Tourism Office (STO) participates in the EOC. Tourism 
officials also need to ensure that there are open lines of communication between emergency management personnel and tourism businesses. Examples of communication activities include:

- Creating announcements about shelters and evacuation routes that can be distributed by businesses to their guests.

- Creating a list of hotels that can stay open during disasters and house recovery workers (such as power company employees) and are willing to serve as quarantine hotels in any season (Palus, 2020).

Any training or outreach initiatives that involve the tourism industry should be conducted in the off-season and needs to include information about public health. For many U.S. coastal destinations, the optimal window for such training is the winter season. This also allows businesses more time to prepare for hurricane season before it arrives, which generally coincides with peak tourism season.

\section{Lessons for destination management organizations}

DMOs carry an important role in uniting the tourism organizations and businesses. For this reason, they should take on the role of the trusted source for the tourism industry regarding risk communication. The four determinants of trust and credibility can shed light on how DMOs can build and maintain trust. Displaying caring and empathy are extremely important factors for building trust and credibility when people are highly concerned, anxious, or fearful. Perceptions of care and empathy can be fostered by engaging in active social listening. These perceptions can also be fostered by mirroring or showing how the DMO understands what the affected person (whether they be an industry stakeholder or visitor) is going through. In order to foster 
perceptions of dedication and commitment, it is important to first identify what the commitment is. If commitment to visitor safety is the focus, for example, the DMO needs to determine how the local tourism industry can show they are dedicated to visitor safety. This can be done through a visitor safety program, such as Visitor Assistance Program implemented by the Lee County Visitor and Convention Bureau, ${ }^{3}$ to help tourists and their families in the case that there is an accidental death or serious injury at the destination (Pennington-Gray \& Schroeder, 2018). The staff act as a liaison in assisting the affected tourist and their family with such things as communicating with law enforcement, assisting with the media, translator services, and navigating foreign embassy regulations.

DMOs can also communicate regularly about their concern for visitor safety and destination resilience, not just when a disaster occurs. The tourism industry can foster perceptions of competence and expertise in keeping visitors safe by showing past good work, using testimonials, and updating visitors regularly on risks and how to stay safe. DMOs can demonstrate their competence and expertise to tourism business owners by attending and organizing resilience workshops (like the ones described in this chapter). They can also provide industry partners with information and resources that can be used to keep resilience at the forefront in their destination. As we learned from the workshops, guest speakers and specific examples are valued information and resources for tourism business owners that can be curated and shared by DMOs.

Inspiring perceptions of honesty and openness are also very important in building trust when people are highly concerned, anxious, or fearful. These perceptions can be fostered by disclosing 
information and always being transparent, even if that means admitting that you do not have the answer but will find out and respond immediately. Failure to do so can undermine existing levels of trust, both with visitors and tourism businesses.

To be considered the go-to trusted source for risk communication, it is important for DMOs to be truthful, frank, honest, and open. It is also important to provide regular updates. In the event of a hurricane, for example, a DMO can use social media to provide instructing information to visitors, use real-time pictures and webcams to provide evidence of current conditions, and use bulletins or newsletters to communicate with industry partners. Having a destination crisis management plan prior to a crisis that includes these types of strategies is important and can demonstrate the DMO's investment in the resilience of the local tourism industry. Another key to being viewed as a trusted source is coordinating, collaborating, and partnering with other credible sources (e.g., NOAA, local emergency management operations, the local health department, etc.). Understanding who is viewed as a credible source in a specific situation is also needed. For example, during the 2010 Deepwater Horizon oil spill, VISIT FLORIDA realized that everyday people were viewed as credible sources. In explaining this strategy, a representative from VISIT FLORIDA stated that:

Floridians were already shooting video, taking pictures, and making useful comments online. So Visit Florida turned Florida Live into a platform that linked residents' tweets and photos to a Google map. And that simple step aggregating the positive content that real Floridians and tourists were already creating - helped reinforce to the public and traditional media that Florida's 
beaches were safe from the oil, at least for sand-castle building purposes (Smalera, 2010).

DMOs also need to ensure that they are communicating clearly and avoiding the use of technical language, as well as using graphics and pictures to reinforce their messages. Visit Okinawa Japan's Typhoon Preparedness Manual is an excellent example of how to communicate typhoon risk to visitors for this reason. It can also be difficult for people to comprehend the severity of a risk. Thus, when possible, DMOs should use comparisons to put risk in perspective. In the aftermath of a severe weather event, disaster, and/or pandemic, establishing the affected destination as a safe one through strategic, research-based marketing is crucial in earning the trust of visitors and getting the tourism industry back up and running. DMOs can also help to connect academic institutions and government agencies that want to offer training and resources to local businesses, especially to small businesses that do not have the resources of major brands.

\section{Lessons for tourism business owners}

If a tourism business is not a member of a local tourism or business association, the owner should ensure they join one. These associations are often a key link between businesses and public officials. Online tools, such as the Coastal Virginia Tourism Business Resilience SelfAssessment described above, and other information are commonly distributed through association meetings or listservs. Businesses that belong to the same association can work together during severe weather events and help one another in the recovery process. Business owners may meet other owners and managers with whom they can partner if there are resiliency measures that are cost prohibitive for one business. 
Business owners and managers must prioritize lines of communication with staff. They could create staff email and phone number lists to efficiently distribute information no matter where staff are located. They should ensure staff members have the resources to prepare their own homes and families for a disaster. The more prepared the staff, the more people will be available to get the business back up and running. Owners and managers should ensure staff all know the same cohesive message that is to be communicated to guests in the event of an impending disaster. They should provide disaster and emergency preparedness training for front-line staff or provide the resources for them to complete it on their own. This training should include health information so that staff can protect themselves and guests during a public health crisis. Frontline staff are the face of the company for the guests; the more staff know, the better they will be able to perform during and after a disaster.

Communicating with guests is much different than communicating with staff. Tourists may not have experienced a hurricane or other disaster before. Being able to clearly communicate accurate safety information will be important because they likely will not know what to do. Owners and managers should develop clear reimbursement policies to put in place when disaster strikes. Businesses that can fairly compensate guests for cancellations will increase the likelihood that guests will return.

Lastly, it is important to remember that resilience is not just the responsibility of tourism businesses. Tourism business owners are not in it alone. Rather, resilience is the responsibility of all members of the tourism system, including DMOs, tourism businesses, and local government 
entities, and those in related sectors such as transportation and retail. Consequently, it is vital that there be collaboration and continuity in risk communication and management practices among these stakeholders to ensure the resilience of the tourism industry.

\section{References}

Atzori, R., and Fyall, A. (2018). Climate change denial: Vulnerability and costs for Florida's coastal destinations. Journal of Hospitality and Tourism Insights, 1(2), 137-149. DOI: https://doi.org/10.1108/JHTI-10-2017-0004

Benjamin, S., Dillette, A., and Alderman, D. H. (2020). "We can't return to normal": Committing to tourism equity in the post-pandemic age. Tourism Geographies. DOI: https://doi.org/10.1080/14616688.2020.1770325

Brehm, S. S., Kassin, S., and Fein, S. (2005). SocialPpsychology (6th ed.). Boston: Houghton Mifflin.

Brown, N. A., Rovins, J. E., Feldmann-Jensen, S., Orchiston, C., and Johnston, D. (2017). Exploring disaster resilience within the hotel sector: A systematic review of literature. International Journal of Disaster Risk Reduction, 22, 362-370. DOI: https://doi.org/10.1016/j.ijdrr.2017.02.005

Calgaro, E., Dominey-Howes, D., and Lloyd, K. (2014). Application of the Destination Sustainability Framework to explore the drivers of vulnerability and resilience in Thailand following the 2004 Indian Ocean Tsunami. Journal of Sustainable Tourism, 22(3), 361-383. DOI: https://doi.org/10.1080/09669582.2013.826231 
Centers for Disease Control and Prevention (2020). Going to a public disaster shelter during the COVID-19 pandemic. Accessed at: https://www.cdc.gov/disasters/hurricanes/covid19/public-disaster-shelter-during-covid.html [Accessed 30 August 2020]

Covello, V. (1992). Risk communication, trust, and credibility. Health and Environmental Digest, 6 (1), 1-4 (April).

Covello, V. (1993). Risk communication and occupational medicine. Journal of Occupational Medicine, 35(1), 18-19.

Dirks, K. T., and Ferrin, D. L. (2001). The role of trust in organizational settings. Organization Science, 12(4), 450-467. DOI https://doi.org/10.1287/orsc.12.4.450.10640

Espiner, S., Orchiston, C., and Higham, J. (2017). Resilience and sustainability: a complementary relationship? Towards a practical conceptual model for the sustainabilityresilience nexus in tourism. Journal of Sustainable Tourism, 25(10), 1385-1400. DOI: https://doi.org/10.1080/09669582.2017.1281929

Hall, C. M. (2006). New Zealand tourism entrepreneur attitudes and behaviours with respect to climate change adaptation and mitigation. International Journal of Innovation and Sustainable Development, 1(3), 229-237. DOI: https://doi.org/10.1504/IJISD.2006.012424

Jiang, Y., and Ritchie, B. W. (2017). Disaster collaboration in tourism: Motives, impediments and success factors. Journal of Hospitality and Tourism Management, 31, 70-82. DOI: https://doi.org/10.1016/j.jhtm.2016.09.004

Leatherman, S. P. (2017). Coastal erosion and the United States Flood Insurance Program. Ocean \& Coastal Management. DOI: http://dx.doi.org/10.1016/j.ocecoaman.2017.04.004 
Li, L. (2005). The effects of trust and shared vision on inward knowledge transfer in subsidiaries' intra- and inter-organizational relationships. International Business Review, 14(1), 77-95. DOI: https://doi.org/10.1016/j.ibusrev.2004.12.005

McCullough, J, and Garnham, J.P. (2020). As Hurricane Laura Heads for Southeast Texas, Officials Scramble to Evacuate and Shelter People During a Pandemic. Accessed at: https://www.texastribune.org/2020/08/26/hurricane-laura-texas-coronavirus/ [Accessed 7 December 2020]

Morgan, M. G., Fischhoff, B., Bostrom, A., and Atman, C. J. (2002). Risk Communication: A Mental Models Approach. Cambridge: Cambridge University Press.

NOAA (2020). Record-breaking Atlantic Hurricane Season Draws to an End. Accessed at: https://www.noaa.gov/media-release/record-breaking-atlantic-hurricane-season-draws-toend [Accessed 7 December 2020]

Palus, S. (2020). We are in desperate need of quarantine hotels. Accessed at: https://slate.com/technology/2020/07/create-quarantine-hotels-now.html [Accessed 30 August 2020]

Pennington-Gray, L., and Schroeder, A. (2018). Crisis concierge: The role of the DMO in visitor incident assistance. Journal of Destination Marketing \& Management, 9, 381-383. DOI: https://doi.org/10.1016/j.jdmm.2018.02.003

Pennington-Gray, L., Schroeder, A., and Gale, T. (2014). Co-management as a framework for the development of a tourism area response network in the rural community of Curanipe, Maule Region, Chile. Tourism Planning \& Development, 11(3), 292-304. DOI: https://doi.org/10.1080/21568316.2014.890124 
Peters, R. G., Covello, V., and McCallum, D. B. (1996). The determinants of trust and credibility in environmental risk communication: An empirical study. Risk Analysis, 17(1), 43-54. DOI: https://doi.org/10.1111/j.1539-6924.1997.tb00842.x

Renn, O., and Levine, D. (1991). Credibility and trust in risk communication. In R. E. Kasperson and P. J. M. Stallen, eds., Communicating Risks to the Public. Kluwer Academic Publishers, pp. 175-218.

Ritchie, B. W. (2004). Chaos, crises and disasters: A strategic approach to crisis management in the tourism industry. Tourism Management, 25, 669-683. DOI: https://doi.org/10.1016/j.tourman.2003.09.004

Smalera, P. (2010) Florida tourism saved by social media. Really. Forbes. Accessed at: http://fortune.com/2010/08/27/florida-tourism-saved-by-social-media-really/ [Accessed 1 August 2020].

U.S. NRC (n.d.). Risk Communication - Principles, Tools, and Techniques. Accessed at: https://www.nrc.gov/docs/ML1015/ML101590283.pdf [Accessed 1 August 2020]

U.S. NRC (n.d.). Effective Risk Communication - The Nuclear Regulatory Commission's Guidelines for External Risk Communication. Accessed at: https://www.nrc.gov/docs/ML0406/ML040690412.pdf [Accessed 7 December 2020]

Usher, L. E., Yusuf, J., and Covi, M. (2019). Assessing tourism business resilience in Virginia Beach. International Journal of Tourism Cities, 6(2), 397-414. DOI: https://doi.org/10.1108/IJTC-02-2019-0019

Visit Okinawa Japan. (2017). Typhoon Preparedness Manual for Visitors Traveling by Plane. Accessed at: https://www.visitokinawa.jp/wpcontent/uploads/2017/07/typhoon_manual_2017.pdf [Accessed 30 August 2020] 
WHO. (n.d.). Risk Communication: General Information on Risk Communication. Accessed at: https://www.who.int/riskcommunication/background/en/\#: :text=Risk\%20communication\%20refers\%20to\%20th e,themselves\%20and\%20their\%20loved\%20ones [Accessed 1 August 2020]

WHO. (2018). Risk Communication: “Can I trust you?” Accessed at: https://www.who.int/riskcommunication/pmac-2018/en/ [Accessed 1 August 2020]

${ }^{1}$ More information about the Tourism Business Resilience for Coastal Virginia Assessment Project is available here: https://www.floodingresiliency.org/tourism/

${ }^{2}$ The Coastal Virginia Tourism Business Resilience Self-Assessment online tool can be accessed here: https://sites.wp.odu.edu/businessresilienceselfassessment/

${ }^{3}$ More information about the Lee County Visitor and Convention Bureau's Visitor Assistance Program is available here: https://www.leevcb.com/the-vcb/visitor-services/visitor-assistance-

program 